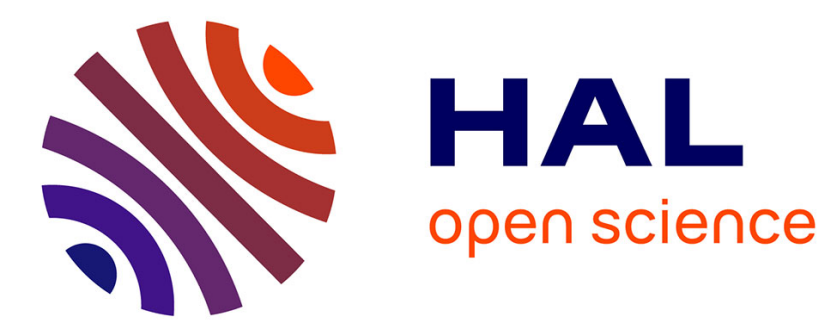

\title{
A wave-to-wire chain modelling and command for a direct drive wave energy converter
}

Hélène Clémot, Florian Dupriez-Robin, Aurélien Babarit, Tuan Tran Quoc

\section{To cite this version:}

Hélène Clémot, Florian Dupriez-Robin, Aurélien Babarit, Tuan Tran Quoc. A wave-to-wire chain modelling and command for a direct drive wave energy converter. Twelfth International Conference on Ecological Vehicles and Renewable Energies (EVER), Apr 2017, Monaco, Monaco. 10.1109/EVER.2017.7935941 . hal-01563330

\section{HAL Id: hal-01563330 \\ https://hal.science/hal-01563330}

Submitted on 25 Apr 2019

HAL is a multi-disciplinary open access archive for the deposit and dissemination of scientific research documents, whether they are published or not. The documents may come from teaching and research institutions in France or abroad, or from public or private research centers.
L'archive ouverte pluridisciplinaire HAL, est destinée au dépôt et à la diffusion de documents scientifiques de niveau recherche, publiés ou non, émanant des établissements d'enseignement et de recherche français ou étrangers, des laboratoires publics ou privés. 


\section{A wave-to-wire chain modeling and command for a direct drive wave energy converter}

Hélène Clémot, Florian Dupriez-Robin

CEA-Tech Pays de la Loire

Technocampus Composites

Chemin du Chaffault

44340 Bouguenais

FRANCE

helene.clemot@ec-nantes.fr

florian.dupriez-robin@cea.fr
Aurélien Babarit

LHEEA Lab

Ecole Centrale de Nantes

1 rue de la Noë BP92101

44321 NANTES Cedex 3

FRANCE

aurelien.babarit@ec-nantes.fr
Tuan Quoc Tran

National Institute of Solar Energy (INES)

CEA-LITEN/DTS/LSEI

Technopôle Savoie Technolac

50 Av. du Lac Léman

73370 Le Bourget-du-Lac

FRANCE

quoctuan.tran@cea.fr

\begin{abstract}
Power quality is an important issue for wave energy developers, as the wave energy converters output power profile presents a lot of fluctuations due to the oscillatory nature of the waves. In order to emulate an operating direct drive wave energy converter, study power quality improvement and test different control strategies, a wave-to-wire model has been developed.

Although control study for wave energy converters is often limited to the hydrodynamic control, this paper addresses the dynamic modeling of all the conversion stages, from the waves to the electric network. First, the wave energy converter used for this study is presented and a model for the electric parts is proposed (including a back-toback converter). Then, control strategies are discussed, in order to regulate the generator electromagnetic torque, the DC-link voltage and the grid voltages and reactive power. Simulation results considering these control strategies are presented in the last part.
\end{abstract}

Index Terms-Wave energy, energy conversion, wave-towire, torque regulation, reactive power regulation, voltage regulation

\section{INTRODUCTION}

Wave energy presents a significant energetic potential that still remains nearly unexploited: the total estimated power of incident waves on coastal areas in the world (neglecting the Poles and some small islands) is about 2 TW. [1]

The idea of harvesting wave energy is not new, the first patent for a system making use of heave movement due to the waves has been written in 1799 , but it is nowadays a highly topical issue. Numerous technologies have been designed in order to harvest this energy but, at the present time, none of them are ready to be commercially used. One of the important issues encountered for wave energy converters development is the grid integration of the devices. Indeed, the output power profile presents a lot of fluctuations due to the oscillatory nature of the resource. As an example, figure 1 shows an output power profile from a direct drive wave energy converter, namely the SEAREV, that has been developed at Ecole Centrale de Nantes for a sea-state $(\mathrm{Hs}, \mathrm{Tp})=(3 \mathrm{~m}, 9 \mathrm{~s})$ (wave height and peak period).

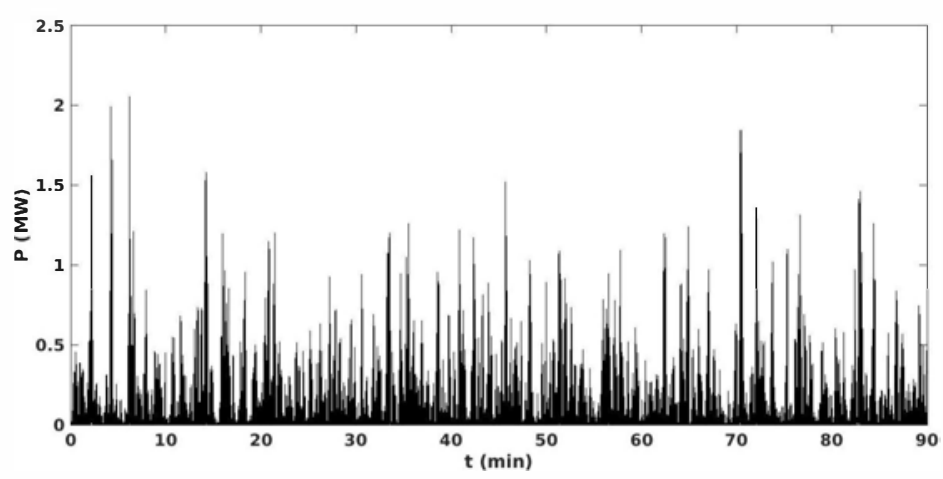

Fig. 1: Power output profile for the SEAREV for a sea state $\mathrm{Hs}=3 \mathrm{~m}$ and $\mathrm{Tp}=9 \mathrm{~s}$

A wave energy converter is composed of three different parts: a reaction mechanism, set in motion by the waves (energy capture device ECD), a system to convert mechanical energy into electrical energy (power take-off PTO) and a control system aimed to adjust the dynamic behavior of the wave energy converter to the incident wave. For floating systems, different PTO can be considered. Two main principles are emerging: indirect conversion (hydraulic PTO) and direct conversion (electric PTO). This study focuses on direct drive wave energy converters.

Power quality is especially an issue for direct drive wave energy converters [2]. Indeed, if the direct conversion of mechanical energy into electrical energy through a generator is more efficient and provides less losses 
than a conversion using a hydraulic interface, there is no power smoothing as the one accomplished by the hydraulic part.

Control of wave energy converters often focuses on hydrodynamic control to absorb maximum power from the ocean waves, and generally simplifies significantly the performances of the power take-off. This paper considers the incorporation of all the conversion stages (from the wave to the grid) to an hydrodynamical wave energy converter model. This model is referred to as a wave-to-wire model. It has been developed using Simulink and more specifically the toolboxes Simscape and SimPowerSystems, which are made for electrotechnics systems and power electronics modeling. Figure 2 shows a scheme of the model.

The wave-to-wire model aims to be used to test and validate control strategies for a grid-connected wave energy farm, to study power quality of wave energy converter devices and to access all information needed (voltages and currents, active and reactive power and electromagnetic torque among others).

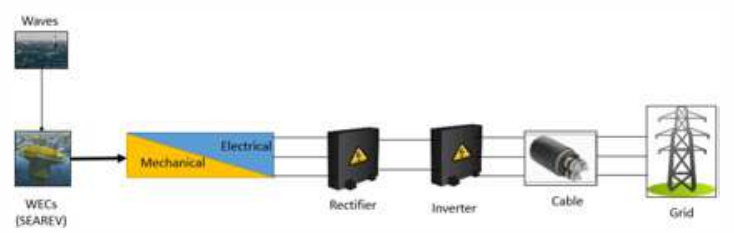

Fig. 2: scheme of the wave to wire simulink model

\section{A WAVE-TO-WIRE MODEL}

\section{A. The wave energy converter}

The chosen case study is the SEAREV, a wave energy converter developed by the LHEEA laboratory at Ecole Centrale de Nantes [3]. The principle of this device is a floating body enclosing a heavy horizontal axis wheel. The center of gravity of the wheel being offcentered, this component behaves mechanically like a pendulum with the wave's action. Two Power Take-Off (PTO) have been considered for this device, a hydraulic one and a direct-drive. The last one is studied here: the rotational motion of the pendular wheel relative to the hull activates a permanent magnets synchronous generator, as described in [4].

Figure 3 gives an illustration of the SEAREV.

The hydrodynamical model used for the WEC has been developped at the LHEEA laboratory. It is a time domain state equation model [6]. It allows, for a given sea state (Hs, Tp), the obtaining of a movement profile for the SEAREV and a mechanical power profile. The

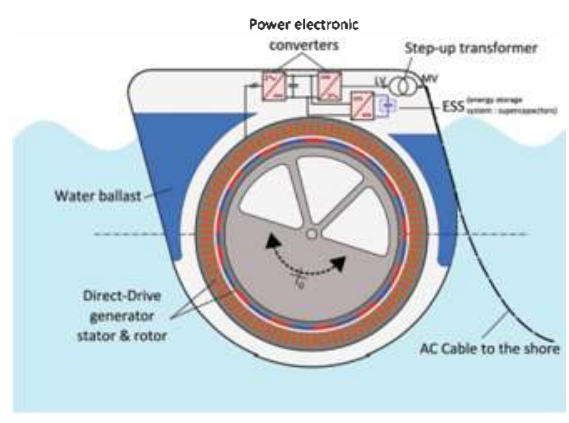

Fig. 3: scheme of the SEAREV wave energy converter (all electric version)[5]

generator exerts a damping force on the WEC (PTO's force) so the electromagnetic torque created in the generator is also used as an input for the WEC model.

The rotational velocity extracted from the SEAREV model is the input of the permanent magnet synchronous generator model.

The generator model is a model from the Simulink SimPowerSystems toolbox.The generator parameters have been determined according to the optimization realized by J. Aubry in [5]. Flux linkage established by magnets (constant flux $\lambda(\mathrm{Wb})$ per poles pairs induced in the stator) is calculated using equation 1 .

$$
\lambda=\frac{V_{\text {peak }}}{(2 * \pi * f)}
$$

Where

- $V_{\text {peak }}$ is the machine nominal peak voltage $(\mathrm{V})($ here, $V_{\text {nom }}=\sqrt{2} * 800=1131 \mathrm{~V}$ )

- $\mathrm{f}$ is the system nominal frequency $(\mathrm{Hz})$ (here $\mathrm{f}=50 \mathrm{~Hz}$ )

\begin{tabular}{|c|c|}
\hline Parameter & Value \\
\hline Pole pairs & 124 \\
\hline Stator phase resistance & $24.3 \mathrm{~m} \Omega$ \\
\hline Armature inductance & $0.4 \mathrm{mH}$ \\
\hline Flux linkage established by magnets & $3.7 \mathrm{~V} . \mathrm{s}$ \\
\hline
\end{tabular}

TABLE I: Simulation parameters

\section{B. Back-to-back converter}

Variable speed generator cannot be directly connected to the grid. Power converters help to improve the power quality in order to meet the grid requirements while allowing the speed to vary, to generate more power. This allows voltage conversion as well as control of the energy flux.

The decoupling between the generator and the electric grid is made here by the creation of a DC bus, with a back-to-back converter (AC-DC-AC converter), as represented in figure 2. 
In this model, the rectifier is not controlled, based on the knowledge gained from wind energy field, where diode rectifier based unidirectional converter and back-to-back bidirectional converter topologies are commonly used, as a cost effective choice and because it is simpler to implement. The drawbacks of the diode rectifier is the large amount of harmonics produced, which can affect the performances of the system, and the fact that the power can only go one direction [7]. A boost chopper adapts the voltage to the DC bus.

Electronic converters can be represented by two types of models: switching models, representing all the switching events, and average-value models (or middle fidelity models).

Average value models allow to limit calculation time and effort to the minimum during the simulations of power electronics systems. Indeed, switching events require a large part of the computational power used. Simulation models including switching frequencies around $100 \mathrm{kHz}$ necessitate at least 4 calculation points with simulation time around $10 \mu$ s to calculate this switching events. The use of average models increases the simplicity of the implementation and use of the models, while keeping a sufficient precision in the model validity domain. As long as the losses are considered it can be sufficient to consider the dynamic behavior of the converter, only average values and RMS are calculated for currents and voltages. Harmonics due to switching events are not represented, as signals are averaged on a cutting period. Average-value models represent the average behavior of the system during two switching events. They consist in calculating moving average on a time window $\mathrm{T}$ (where $f_{s}=\frac{1}{T}$ is the switching frequency), considering two space states: switch open (off) or close (on) [10] [9].

Power converter models can be divided into two parts:

- Linear elements, non-varying with time, whose structure does not depend on the switching events $(\mathrm{L}, \mathrm{C}, \ldots)$

- Non-linear elements and control part (switches, diodes, ...)

Non linear elements are replaced by voltage and current controlled sources, representing the relations between average currents and voltages (these two sources can be modeled by an ideal transformer with a relevant equivalent transformation ratio). For the inductance, current variation during a cutting period can be calculated integrating average voltage and for capacitors voltage variation is calculated integrating average current.

Average value models are used for the DC/DC converter and the DC/AC converter, in this model. Figures 4 and 5 present these models in comparison with detailed switching models.

For the inverter average model, the signal for the controlled current source corresponds to the DC link current, as calculated in equation 2 .

$$
I_{D C}=\frac{P_{D C}}{V_{D C}}
$$

Where:

- $V_{D C}=\int_{0}^{T} \frac{I_{D C}+I_{\text {diode }}}{C_{D C}} . d t$

- $P_{D C}=P_{A C}=V_{a b} * I_{a}-V_{b c} * I_{c}$

- $I_{a}$ and $I_{b}$ are measured at the output of the inverter.

For the voltage signals, equations 3 are obtained from the inverter scheme in figure 5(b) [8].

$$
\begin{gathered}
V_{s 1}=\frac{1}{6} *\left(2 U_{1}-U_{2}-U_{3}\right) * V_{0} \\
V_{s 2}=\frac{1}{6} *\left(-U_{1}+2 U_{2}-U_{3}\right) * V_{0} \\
V_{s 3}=\frac{1}{6} *\left(-U_{1}-U_{2}+2 U_{3}\right) * V_{0}
\end{gathered}
$$

Where:

- $V_{s} i$ (i being the inverter branch number as defined in figure 5(b)) are the inverter's AC voltages relative to the grid neutral.

- $U_{i}$ are the switching functions ranging between -1 and +1 .

- $V_{0}$ is the DC bus voltage.

Voltage signals used in this model are calculated in equations 4 and 5

$$
\begin{aligned}
& V_{a b}=V_{s 1}-V_{s 2}=\frac{1}{2} * V_{0} *\left(U_{1}-U_{2}\right) \\
& V_{b c}=V_{s 2}-V_{s 3}=\frac{1}{2} * V_{0} *\left(U_{2}-U_{3}\right)
\end{aligned}
$$

\section{Wires and electrical grid}

Three phase transmission lines are represented with a PI sections, which implies that the $\mathrm{R}, \mathrm{L}$ and $\mathrm{C}$ parameters are gathered in a single section and not uniformly distributed in the line. The use of PI sections leads us to work with a finite number of states and then to compute a linear state-space model, whereas distributed lines models imply an infinite number of states. This model is valid for only one frequency of interest and one particular line length.

Figure 6 illustrates the PI section as it is modeled in the SimPowerSystems block. $R_{s}$ and $R_{m}$ are the self and mutual resistances of the three coupled inductors, 


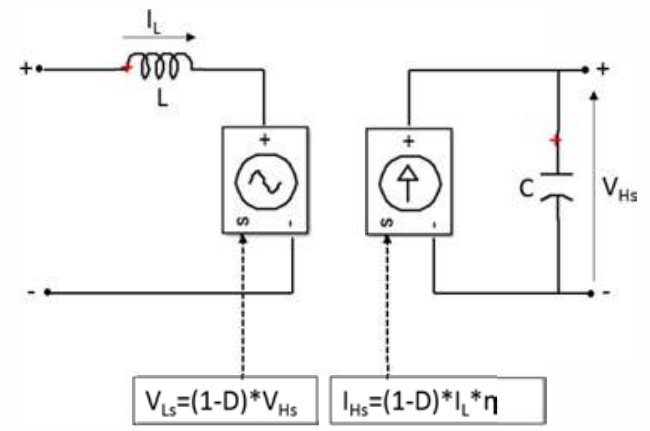

(a)

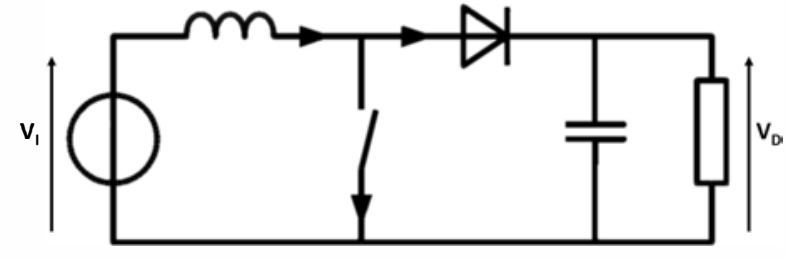

(b)

Fig. 4: Boost converter average (a) and switching (b) models

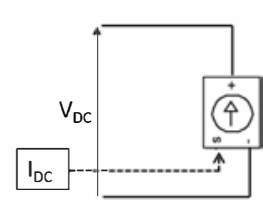

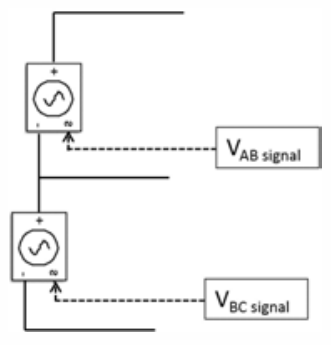

(a)

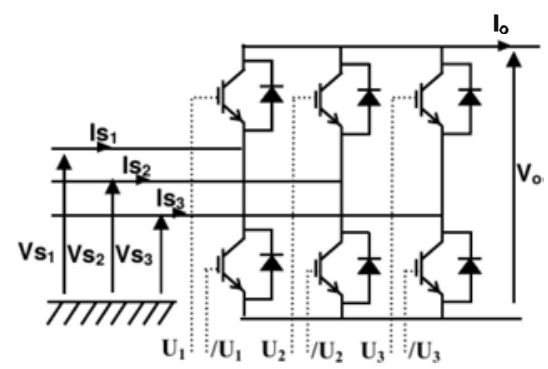

(b)

Fig. 5: Inverter average (a) and switching (b) models

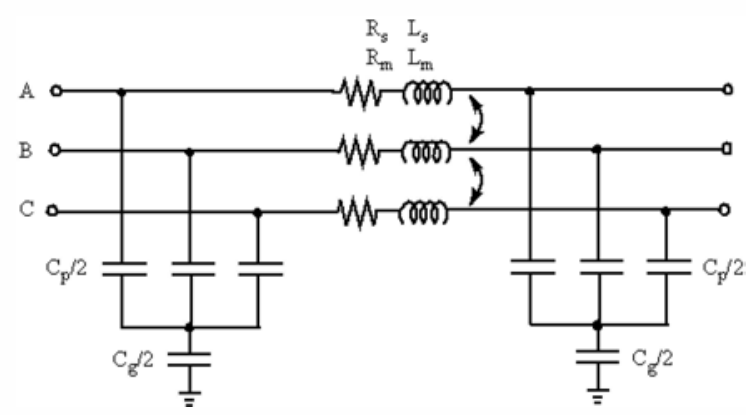

Fig. 6: PI section

$L_{s}$ and $L_{m}$ their self and mutual inductances and $C_{p}$ and $C_{g}$ are the phase and ground capacitances.

Here, the cable is considered as $10 \mathrm{~km}$ long.

The electrical grid is modeled with a three-phase voltage source in series with an impedance. Here, the grid impedance angle is $35^{\circ}(\mathrm{X} / \mathrm{R}=0.7)$, the base voltage is $20 \mathrm{kV}$ and the 3-phase short circuit level at base voltage is 50MVA.

\section{CONTROL STRATEGIES}

\section{A. Torque regulation}

The electromagnetic torque generated by the synchronous machine is controlled by the boost converter in order to recover the optimal amount of energy for each state encountered by the wave energy converter. The regulation is done using boost inductor current. The control scheme is represented in figure 7 .

The optimal electromagnetic torque at each time step is calculated using equation (6), where $\omega$ is the pendulum rotational velocity $\left(\mathrm{rad} . \mathrm{s}^{-1}\right.$ ) and $\beta_{o p t}$ is the optimal damping coefficient $\left(\mathrm{Nm} /\left(\operatorname{rad} . \mathrm{s}^{-1}\right)\right)$. This last one has been determined by maximization of the mechanical mean power using the SEAREV hydrodynamical model for each sea-state (Hs, Tp).

$$
\mathrm{Tem}^{*}=\beta_{\text {opt }} * \omega(t)
$$

A power clipping is also introduced here (algorithm 1) in order to decrease the output peak power and thus the sizing of the power electronics, whitout loosing too much 


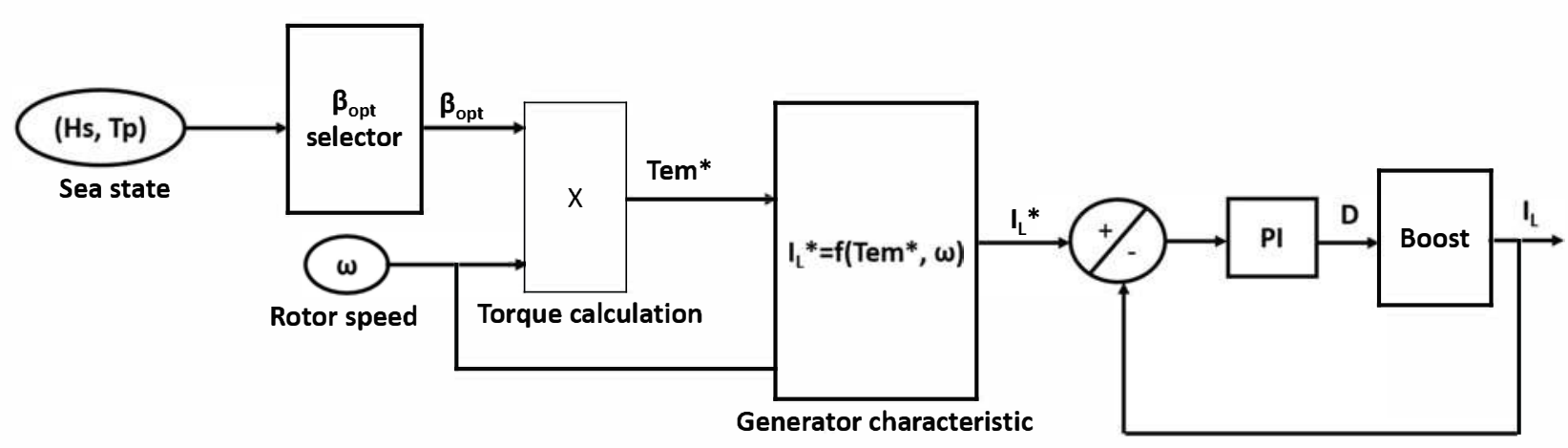

Fig. 7: Torque regulation scheme

mean power [5].

$$
\begin{aligned}
& \text { if } P_{\text {elec }}(t)<P_{\text {clipping }} \text { then } T_{\text {ref }}(t)=\beta_{\text {opt }} * \omega(t) \\
& \text { else if } P_{\text {elec }}(t) \geq P_{\text {clipping }} \text { then } T_{\text {ref }}(t)=\frac{P_{\text {clipping }}}{\omega(t)}
\end{aligned}
$$

Algorithm 1: Power clipping

Once the reference torque is calculated, it is used to determine the reference current with the help of the generator characteristic $I_{L}^{*}=f\left(\mathrm{Tem}^{*}, \omega\right)$. This function has been determined for one specific parameters batch for the generator model, by measuring the output torque from the generator for different couples $\left(\omega, I_{L}\right)$.

The reference current corresponds to the boost inductance current $\left(I_{L}\right)$. The control is based on a classical PI controller, as shown in figure7.

\section{B. DC link voltage and reactive power regulation}

In this model, vector current control has been used for DC link voltage and reactive power regulation. The principle of this regulation is to control instantaneous active and reactive grid currents independently [11]

Current and voltage signals are transposed from the abc frame to the dq frame with a Clark-Park transformation. Three phase components are described as vectors in a stationary $(\alpha \beta)$ frame (Clarke transformation), then they are transformed to the rotating (dq) coordinate system (Park transformation) (figure 8). The Clarke transformation is performed using relation 7 .

$$
[h]\left[\begin{array}{l}
u_{\alpha} \\
u_{\beta}
\end{array}\right]=\frac{2}{3}\left[\begin{array}{ccc}
1 & \frac{-1}{2} & \frac{-1}{2} \\
0 & \frac{\sqrt{3}}{2} & \frac{-\sqrt{3}}{2}
\end{array}\right]\left[\begin{array}{l}
u_{a} \\
u_{b} \\
u_{c}
\end{array}\right]
$$

Vectors $u_{\alpha}$ and $u_{\beta}$, representing the stationary frame, rotate with the angular speed $\omega(t) . \theta$ is the angle defined by integrating $\omega(t)$. Park transformation can be written as in equation 8.The matrix presented in equation 9 is

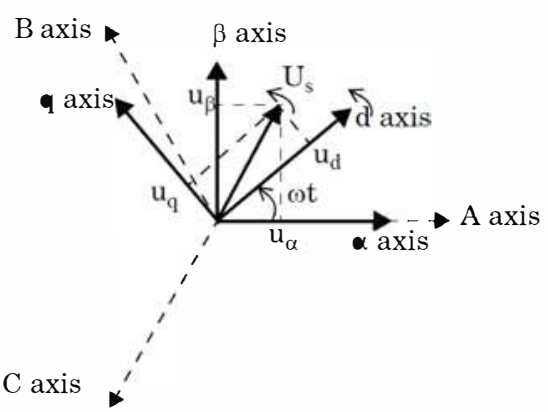

Fig. 8: Combined reference frames for Park transformation

then obtained.

$$
U_{d q}=X_{\alpha \beta} e^{-j \theta}
$$

$$
\left[\begin{array}{l}
u_{d} \\
u_{q}
\end{array}\right]=\left[\begin{array}{cc}
\cos (\theta) & \sin (\theta) \\
-\sin (\theta) & \cos (\theta)
\end{array}\right] \times\left[\begin{array}{l}
u_{\alpha} \\
u_{\beta}
\end{array}\right]
$$

Reactive current $i_{q}$ is used to control reactive power flow into the grid while active current $i_{d}$ is used to control the DC-link voltage level.

The control loop is presented in figure 9 , where $I_{a b c}$ is the current measured after the inverter and $e_{d}$ and $e_{q}$ are grid neutral voltages.

The reference voltages $v_{q}^{*}$ and $v_{d}^{*}$ from the PI controllers are transposed into the (abc) frame using the Clarke-Park inverse transformation and the voltage reference $U_{a b c}$ is used to calculate $U_{a b}$ and $U_{b c}$ for the inverter average model, as presented in equations 4 and 5.

In this model, the reactive power regulation is coupled with a grid-voltage regulation (VAR/Volt regulation). The goal of VAR/Volt regulation is to ensure that the electrical utilities deliver power within appropriate voltage limits so that consumers equipment operates 


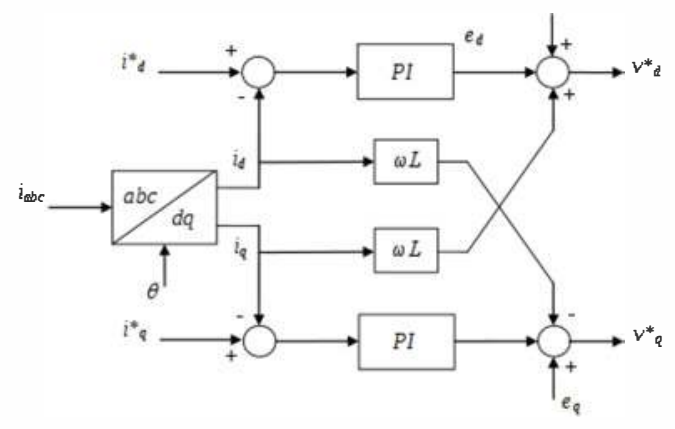

Fig. 9: Grid converter current control loop

properly, and that the power has an optimal power factor in order to minimize losses.

Block diagrams for reactive power regulation and DC link voltage regulation can be seen in figures 10 and 11 .

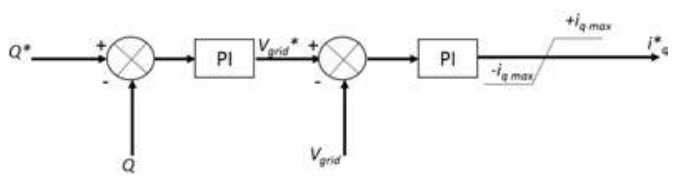

Fig. 10: Reactive power and grid voltage regulator block diagram

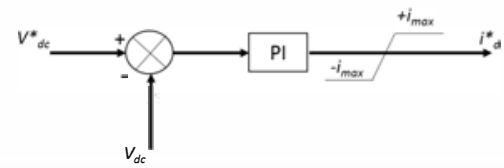

Fig. 11: DC voltage regulator block diagram

\section{Simulation RESUlTS}

This section illustrates a simulation performed with the wave-to-wire model (figure 2 and figure 12) described in this article.

The wave energy converter is the SEAREV and the sea-state considered for the results presented in this section is constant: $(\mathrm{Hs}, \mathrm{Tp})=(3 \mathrm{~m}, 9 \mathrm{~s})$. The users have the possibility to choose a constant sea-state (that can be changed at any time during the simulation) or a time serie of pre-saved sea-states, corresponding to the seastates measured during one year at the SEM-REV marine energy test site (located west of Le Croisic peninsula, in the north-west of France).

The goal of the control strategies implemented on the wave-to-wire model is to keep the grid voltage, power and frequency in compliance with the grid codes, and to optimize the energy quantity harvested with the wave energy converter.

The parameters used for the simulation are presented in table II.

\begin{tabular}{|c|c|}
\hline Parameter & Value \\
\hline Sea state $(\mathrm{Hs}, \mathrm{Tp})$ & $(3 \mathrm{~m}, 9 \mathrm{~s})$ \\
\hline Optimal viscous damping coefficient & $6.10^{6}\left(\mathrm{Nm} /\left(\mathrm{rad}_{\mathrm{s}}{ }^{-1}\right)\right)$ \\
\hline Clipping power & $0.5 \mathrm{MW}$ \\
\hline Grid frequency & $50 \mathrm{~Hz}$ \\
\hline Grid-side converter nominal AC voltage & $500 \mathrm{~V}$ \\
\hline Nominal DC bus voltage & $1100 \mathrm{~V}$ \\
\hline
\end{tabular}

TABLE II: Simulation parameters

The pendulum rotational velocity is presented in figure 13. This is also the permanent magnet synchronous generator rotor speed.

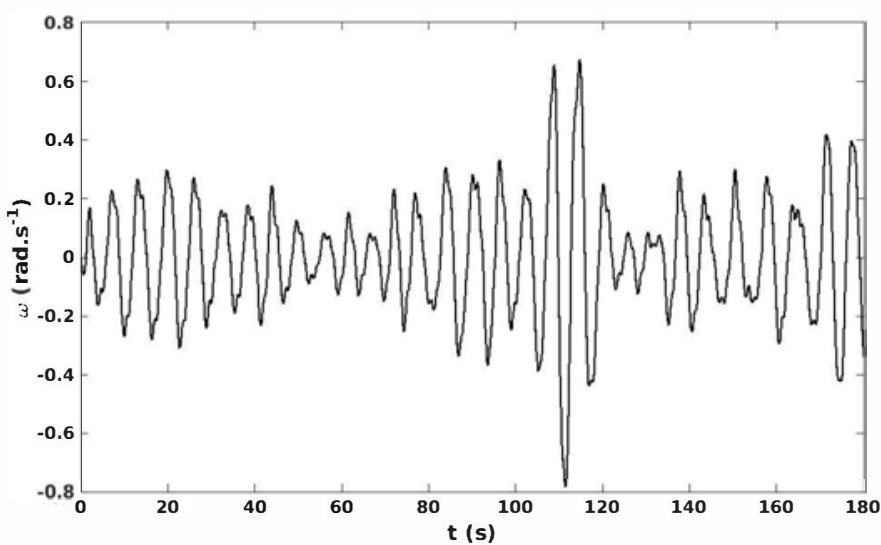

Fig. 13: Rotor speed $\left(\operatorname{rad} . s^{-1}\right)$

Torque regulation is illustrated on figure 14. This regulation is performed by regulating the boost inductance current (figure 15). It can be observed that the torque is responding well to this control and the clipping is respected. The clipping power is set to $0.5 \mathrm{MW}$ in this study. Figure 16 is a zoom of figure 14. It shows how the regulation is done when the mechanical power exceeds the clipping power. It can be seen that there is a small time window during which the torque is not regulated as well as the rest of the time (when the reference torque ramp is elevated, for high velocity). This explains that the power clipping is not perfectly performed due to the torque overshoot during the regulation at high velocity. The power overshoot exceeds $30 \%$ of the clipping power.

Figure 18 shows the DC link regulation. A very stressful start-up occurs with the DC-link voltage reaching $2900 V$. Some measures need to be taken to avoid this peak. The response of the dc voltage is slow $(2.5 \mathrm{~Hz})$. 


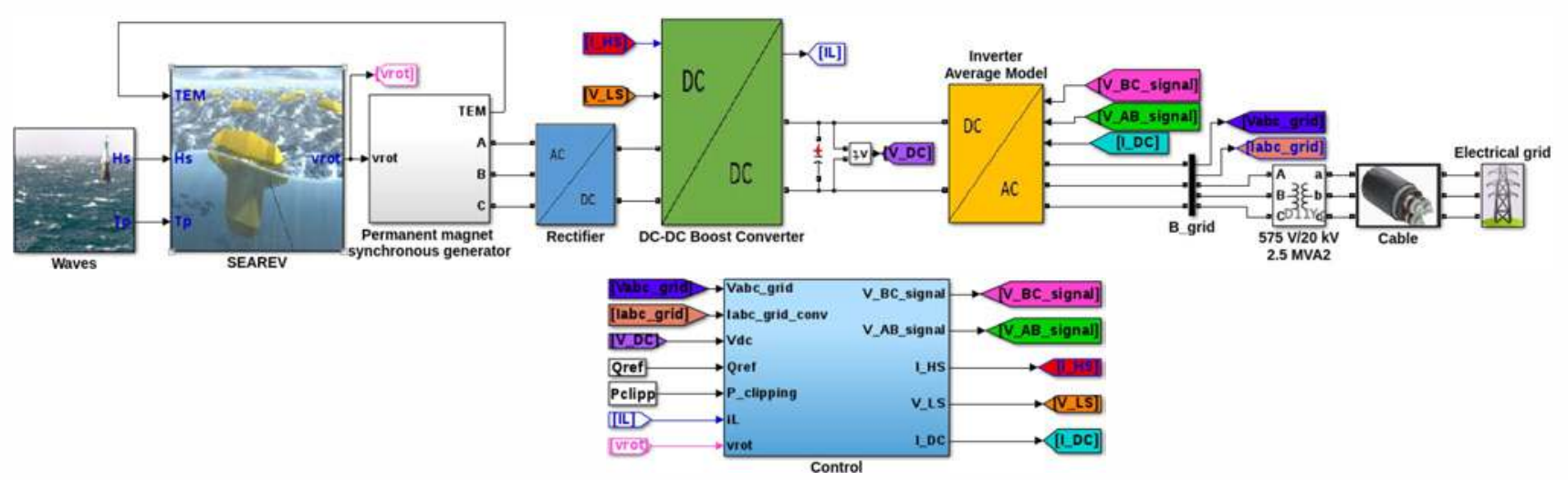

Fig. 12: Simulink scheme of the wave-to-wire model

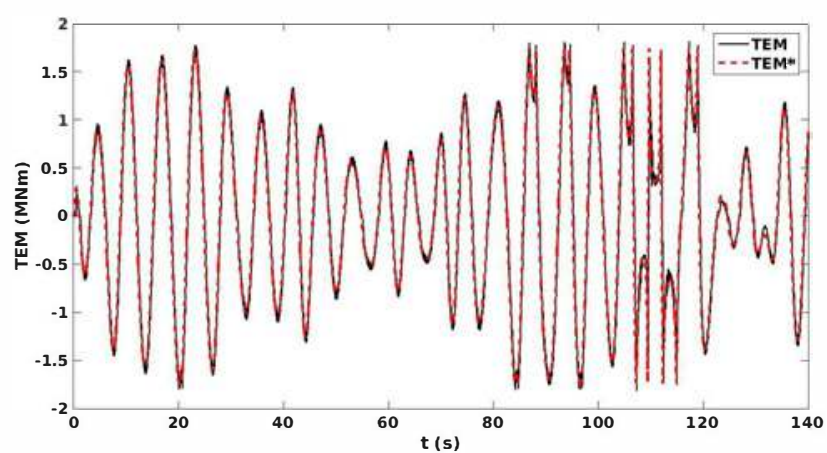

Fig. 14: Permanent magnet synchronous generator output torque and reference torque

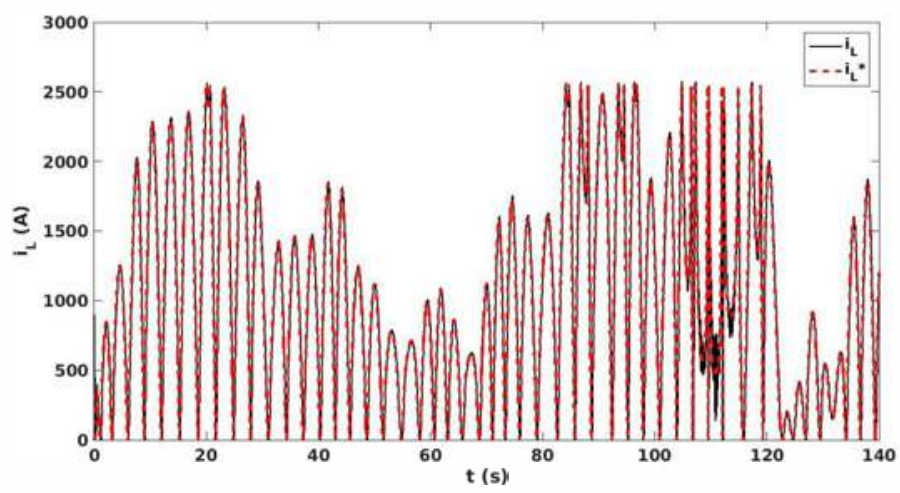

Fig. 15: Boost inductance current and reference current

Figures 19 and 20 present the reactive power and grid voltage regulations. The reference reactive power is set to OVAR.

\section{CONCLUSION}

This article presented a complete wave-to-wire model, with a wave energy converter example: the SEAREV. Control strategies have been implemented to this waveto-wire model in order to optimize the energy quantity

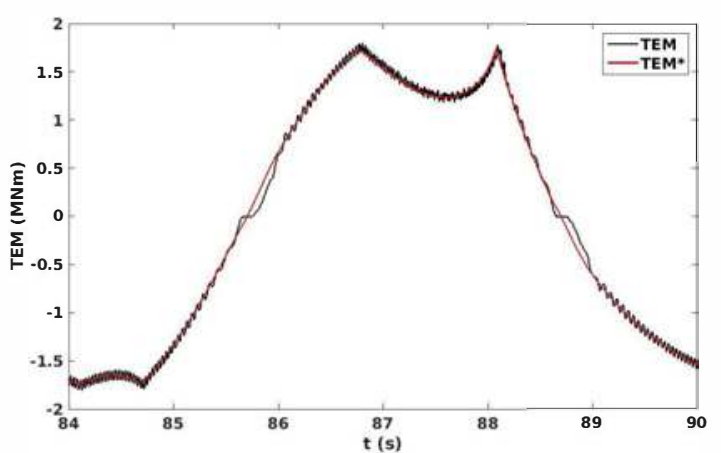

Fig. 16: Permanent magnet synchronous generator output torque and reference torque when the power exceeds the clipping power

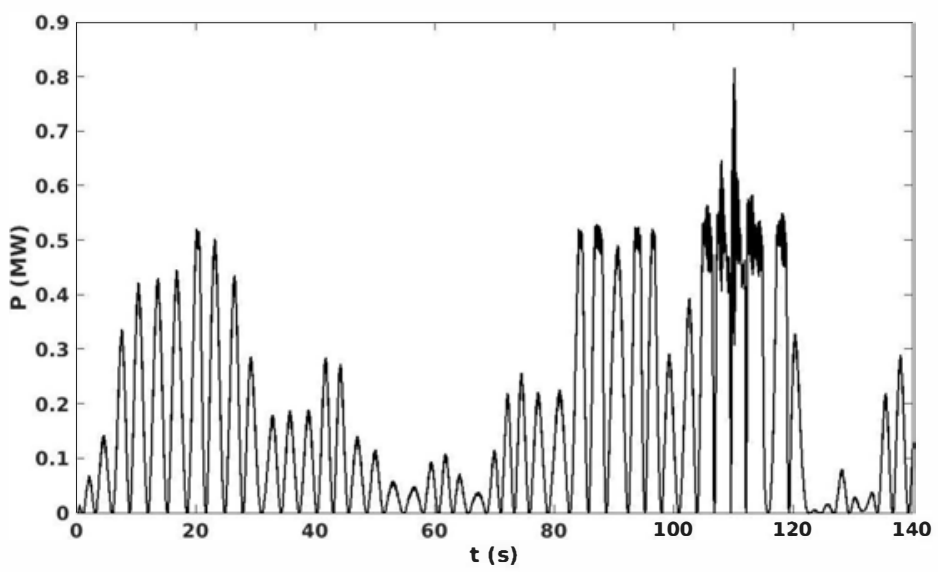

Fig. 17: Mechanical power extracted from the SEAREV (MW)

harvested with the wave energy converter.

Simulations results and regulation performances are presented.

This complete wave-to-wire model can be used to study wave energy quality, and more particularly fast voltage 


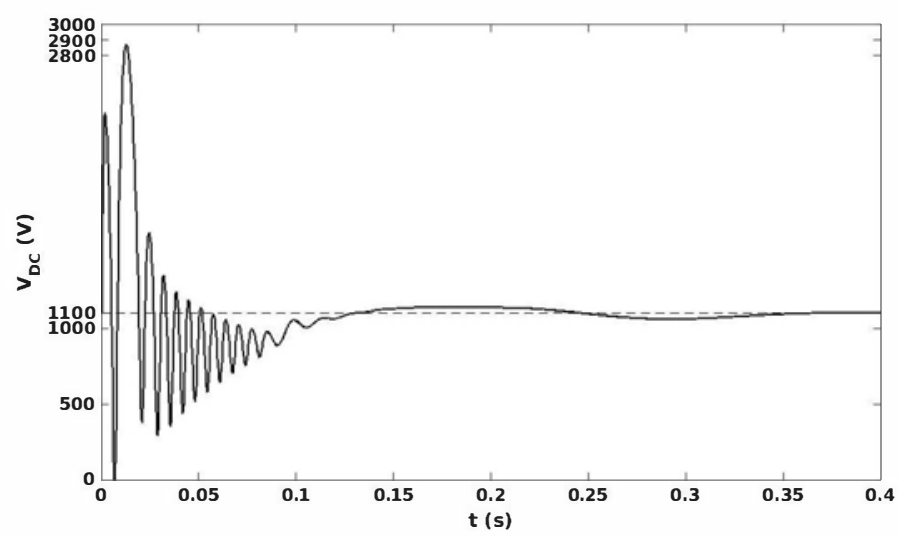

Fig. 18: DC-link voltage regulation performance

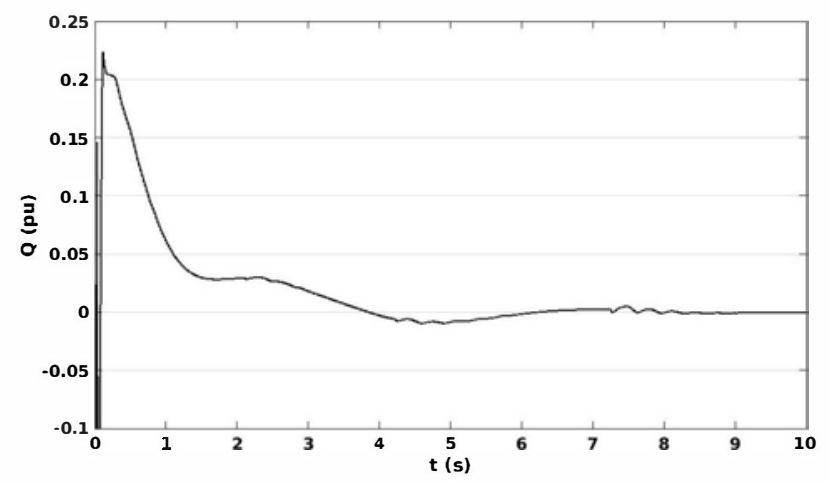

Fig. 19: Reactive power regulation

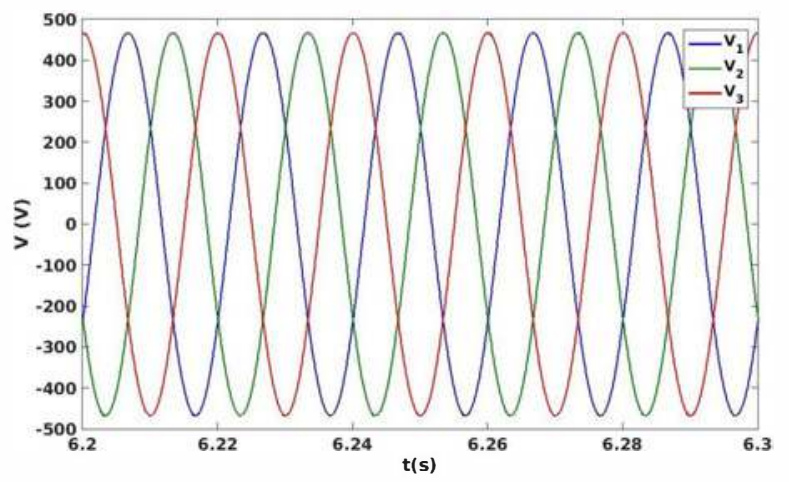

Fig. 20: Grid voltages regulation

fluctuations (or flicker), that can cause variations in light source intensity and bring disturbances for the users and lead to a dysfunction or an early ageing process of the electrical equipments. In order to improve energy quality, it may be necessary to introduce an energy storage system on the DC-link, as batteries or supercapacitors.

\section{ACKNOWLEDGMENT}

This work is subsidized by the Pays de la Loire region.

\section{REFERENCES}

[1] Gunn K. and Stock-Williams C., Quantifying the global wave power resource Renewable Energy, 2012, 44, 296 - 304

[2] Baker N. and Mueller M., Direct drive wave energy converters Revue des Energies Renouvelables, du centre des Energies Renouvelables d'Algérie, 2001, 1-7

[3] Cordonnier J.; Gorintin, F.; Cagny, A. D.; Clément, A. and Babarit, A., SEAREV: Case study of the development of a wave energy converter Renewable Energy, Elsevier BV, 2015, 80, 4052

[4] Ruellan M., Méthodologie de dimensionnement d'un système de récupération de l'énergie des vagues, Ecole normale supérieure de Cachan, 2007

[5] Aubry J., Optimisation du dimensionnement d'une chaîne de conversion électrique directe incluant un système de lissage de production par supercondensateurs.Application au houlogénérateur SEAREV, Ecole normale supérieure de Cachan, 2011

[6] Babarit, A.; Clement, A. H. and Gilloteaux, J.-C., Optimization and Time-Domain Simulation of the SEAREV Wave Energy Converter, 24th International Conference on Offshore Mechanics and Arctic Engineering: Volume 2, ASME, 2005

[7] Islam, M. R. and Guo, Y. and Zhu, J., Power converters for wind turbines: current and future development Materials and processes for energy: communicating current research and technological developments. Energy Book Series-2013 edn. Spain, 2013, 559571

[8] Gombert, C. Simulation temps-réel des dispositifs d'Electronique de Puissance dédiés aux réseaux d'énergie électrique, Institut National Polytechnique de Grenoble - INPG, 2005

[9] Middlebrook R. D. and Cuk S., A general unified approach to modelling switching-converter power stages, Power Electronics Specialists Conference, 1976 IEEE, 1976, 18-34

[10] Sanders, S. R.; Noworolski, J. M.; Liu, X. Z. and Verghese, G. C., Generalized averaging method for power conversion circuits, IEEE Transactions on Power Electronics, 1991, 6, 251-259

[11] Svensson, J. Grid Connected Voltage Source Converter - Control Principles and Wind Energy Applications, Department of Electrical Power Engineerin, Chalmers University of Technology, 1998 